\title{
Impact of an invasive predatory lizard on the endangered Hawaiian tree snail Achatinella mustelina: a threat assessment
}

\author{
Luciano M. Chiaverano, Brenden S. Holland*
}

Pacific Biosciences Research Center, University of Hawaii at M noa, 1993 East-West Road, Honolulu, Hawaii 96822, USA

\begin{abstract}
All 41 species of the Hawaiian tree snail genus Achatinella were listed as endangered in the early 1980s, primarily due to predation by invasive species. Today, only 9 species are estimated to remain. The recent discovery of $A$. mustelina in gut contents of Jackson's chameleons Trioceros jacksonii xantholophus, a predatory arboreal African lizard introduced to Hawaii (USA) in 1972, was the first documentation of environmental impact by any reptile on native Hawaiian taxa. In this study, we assessed the predatory threat posed by chameleons to A. mustelina by (1) determining shell digestion and passage rates in daily fed and fasting individuals and (2) using these data to estimate time of ingestion of snails found in guts of field-collected chameleons. Our results indicate that daily food intake increases passage rate. Well fed chameleons passed largely intact $A$. mustelina shells in $\sim 4$ to $5 \mathrm{~d}$, whereas starved individuals retained shells in their stomachs until complete digestion in $\sim 8 \mathrm{~d}$. Shell mass was digested at $\sim 12.5 \% \mathrm{~d}^{-1}$. In total, 8 A. mustelina were found in 45 field-collected lizards, and estimated time of ingestion, based on shell condition, was $\sim 3$ to $4 \mathrm{~d}$ prior to capture in all cases. Given a predator density of 45 per $2000 \mathrm{~m}^{2}$ (0.5 acre) and assuming a feeding frequency of 8 snails every 3 to $4 \mathrm{~d}$, we conservatively estimate that 45 chameleons could consume 730 to 974 snails $\mathrm{yr}^{-1}$, per $2000 \mathrm{~m}^{2}$. Given the low growth and reproductive rates of Hawaiian tree snails, this level of impact is probably unsustainable even over the short term, and immediate control action is warranted.
\end{abstract}

KEY WORDS: Jackson's chameleon - Trioceros jacksonii xantholopus · Endemic invertebrate conservation · Resource management · Invasive species control

\section{INTRODUCTION}

The terrestrial ecosystems of the Hawaiian Islands (USA) rank among the most isolated and threatened on Earth (Dobson et al. 1997). Geographic isolation combined with habitat diversity has resulted in extraordinary levels of endemism: approximately $95 \%$ of the native terrestrial Hawaiian plant and animal species are endemic (Carlquist 1970). In recent decades, the Hawaiian flora and fauna have also become recognized for high extinction levels across numerous groups, including land snails, with losses of up to $90 \%$ of the described species (Cowie 2001, Holland
2009). Prior to the intentional release of the predatory snail Euglandina rosea from its native southeastern USA in 1955 by the Board of Agriculture (Mead 1979, Cowie 2001, Holland et al. 2008), the Oahu endemic genus Achatinella represented a highly diverse group, comprising 41 described species (USFWS 1993). Due primarily to predatory activity of invasive taxa, including the black rat Rattus rattus and the flatworm Platydemus manokwari, the entire genus Achatinella was placed on the US Fish and Wildlife Service Endangered Species list in the early 1980s (USFWS 1981). By 1993, 21 species had gone extinct, and 18 of the 20 remaining species persisted only 
in restricted forest patches, in very low numbers (USFWS 1993). Recent surveys continue to reveal a deteriorating scenario (Holland \& Hadfield 2007, D. Sischo pers. comm.), and currently we estimate that only 9 Achatinella species remain (B. Holland pers. obs.).

Primary threats to Hawaiian tree snails come from invasive predators, including rats (Rattus spp.), the wolf snail Euglandina rosea, the flatworm P. manokwari, and, based on a recent revelation, Jackson's chameleon Trioceros jacksonii xantholophus (Holland et al. 2010). Jackson's chameleons are native to montane habitats of Kenya and Tanzania (Spawls \& Rotich 1997, Necas 1999). In 1972, several dozen individuals of this subspecies, the largest of 3, were imported and released on the Hawaiian island of Oahu via the pet trade (McKeown 1991, Waring 1997). In addition to this well-documented release, it has been reported that hundreds of chameleons born in pet stores located on the west coast of the USA were also imported and released at numerous localities in Hawaii by a number of individuals in the early 1970 s, with the intention of establishing a stock of animals to be exported for the pet trade (Kraus et al. 2012). As a result of subsequent decades of humanmediated transport and distribution of specimens among islands, as well as ongoing releases into the wild, $T$. $j$. xantholophus spread rapidly throughout most of the state, becoming established in multiple areas on all major Hawaiian Islands (with the possible exception of Kauai) by the mid 1990s (McKeown 1991, Kraus et al. 2012). Although chameleons have not been legally exported from Kenya to Hawaii since 1981 (McKeown 1996), and regulations took effect in the late 1990s aimed at thwarting transport among islands and prohibiting conveyance out of the state, Jackson's chameleons are still legally sold in pet stores (authors' pers. obs.).

Despite the fact that Jackson's chameleons are predators, and are known to feed on a variety of invertebrate and small vertebrate species, they were not considered a threat to the native Hawaiian fauna (McKeown 1996) until recently, when it was demonstrated for the first time that when present in pristine native Hawaiian forest, chameleons prey on numerous species of endemic arthropods and gastropods, including the Critically Endangered (IUCN 2013) Oahu tree snail Achatinella mustelina (Holland et al. 2010). Since then, Jackson's chameleons have been considered a species of conservation concern in the Hawaiian Islands, and studies of their impacts on native species have recently begun (Kraus \& Preston 2012, Kraus et al. 2012). In a recent study by Holland et al. (2010), tree snail shells that were recovered from the guts of field-collected chameleons were partially digested, although no method was available to estimate time of ingestion. Information regarding digestion rates and relationships of passage time to feeding regime of tree snail shells is critical in terms of gaining an understanding and assessing the severity of the threat posed by Jackson's chameleons. For example, if shells and fragments of crushed shells require relatively long periods of time to digest or pass, i.e. multiple weeks or months, then due to their shear bulk, the shells might impede further feeding, thus limiting or reducing potential impact on endangered tree snail fauna by chameleons. However, if the rate of digestion/passage is relatively rapid, i.e. only a few days, this suggests a potentially elevated impact of chameleon predation on rare snails, as a given population density of lizards would tend to consume more snails in a given amount of time.

Data on shell digestion rates may provide important information in determining the time of consumption, enhance our ability to assess predatory threat, and allow inference regarding movements and dispersal of chameleons (Chiaverano et al. 2014). In the present study, we carried out laboratory experiments to evaluate digestion and passage of $A$. mustelina shells by Jackson's chameleons under different feeding scenarios. We then applied these data to A. mustelina recovered from the guts of Jackson's chameleons collected in the field to estimate time of ingestion and to more accurately assess predatory impact and understand threats posed by Jackson's chameleons to endangered Hawaiian tree snails.

\section{MATERIALS AND METHODS}

\section{Specimen collection for laboratory shell digestion trials}

Jackson's chameleons were collected by hand at night (collection permit: ODF-092611R) from the Tantalus area (Fig. 1) for feeding trials. Individuals were brought to the Hawaiian Tree Snail Conservation Lab (University of Hawaii, Manoa) and maintained under uniform conditions in individual plastic cages $(210 \times 120 \times 120 \mathrm{~mm})$ with tree branches for climbing and perching. Cages had perforated lids and were modified by removal of a rectangular portion of the floor and replacing it with $1 \mathrm{~mm}$ screen, glued into the bottom cage floor to facilitate air flow and water drainage. Cages were hand-misted with tap water at regular intervals and kept at constant temperature $\left(24^{\circ} \mathrm{C}\right)$ in the lab. 


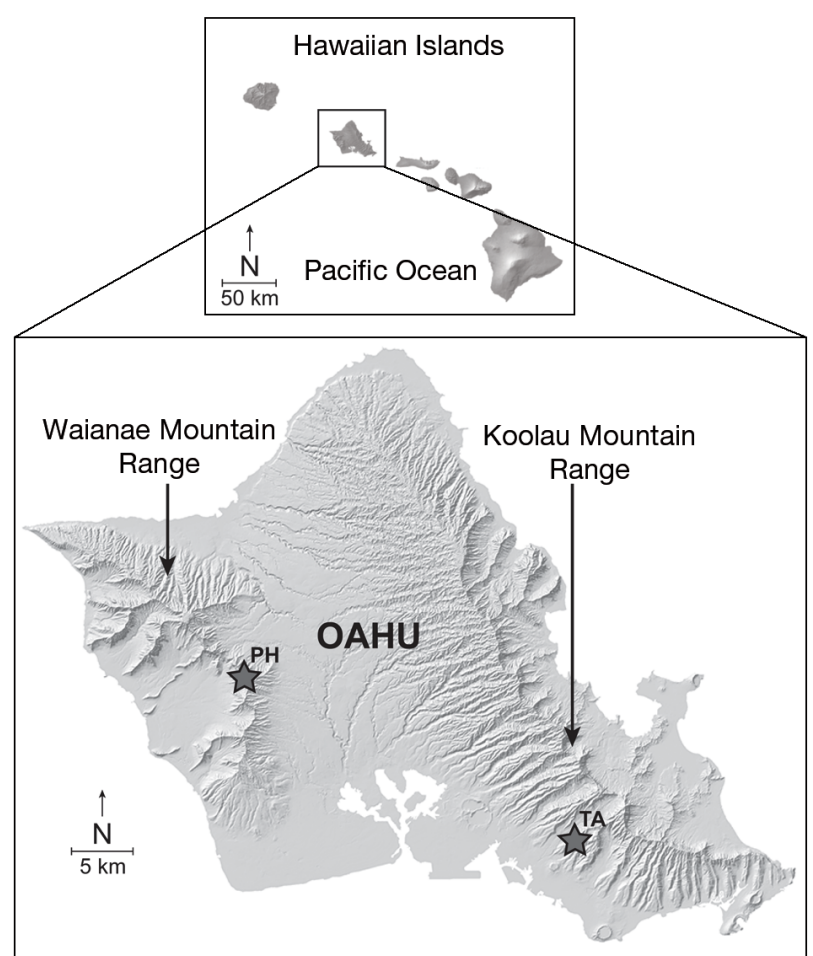

Fig. 1. Main Hawaiian Islands, USA (top), with detailed view of Oahu (bottom), showing collection sites for Jackson's chameleons Trioceros jacksonii xantholophus used for the laboratory feeding trials (TA: Tantalus), and for the gut content analysis (PH: Puu Hapapa)

\section{Experimental approach: feeding trials}

Prior to the experiment, chameleons were starved for $36 \mathrm{~h}$, each individual was weighed, measured for snout-to-vent length (SVL) using a caliper, and sexed. Feeding trials consisted of force-feeding each chameleon 1 fresh Achatinella mustelina shell (Fig. 2), which had been collected as empty ground shells from the northern Waianae Mountains (Puu Hapapa; Fig. 1) (USFWS Endangered Species permit no. TE043638-8). This site is within the natural range and current distribution of A. mustelina as well as a number of other rare endemic snails, arthropods, birds and plants. Since chameleons and tree snail shells varied in size, shells were selected and standardized with initial weight (IWE) of $0.5 \%$ of total chameleon weight. Force-feeding was conducted by manually opening the mouth of the restrained lizard and introducing the shell, orientated with the apex downward, into the mouth, and then gently pushing the shell into the esophagus with a narrow $(0.5 \mathrm{~cm}$ diameter) probe (Fig. 2). Although Jackson's chameleons masticate most arthropod prey, they tend to

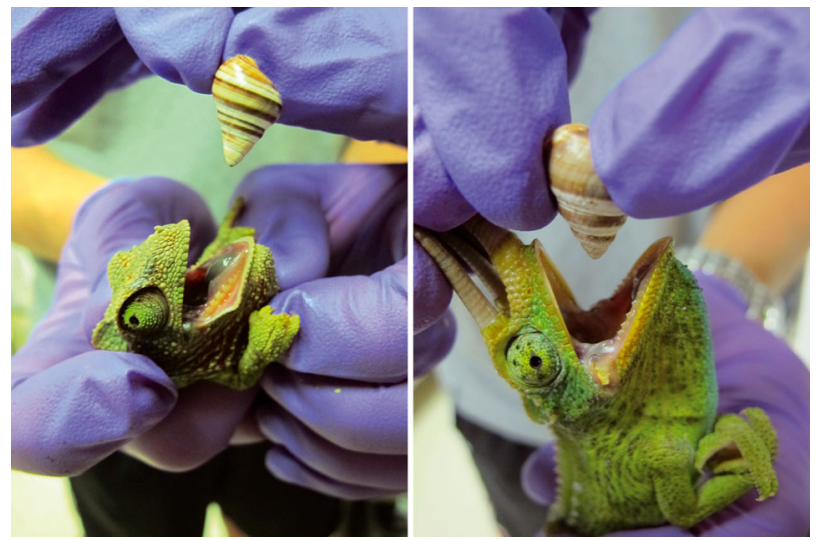

Fig. 2. Force-feeding empty Achatinella mustelina tree snail shells to Jackson's chameleons Trioceros jacksonii xantholophus for laboratory digestion and passage rate trials. Sexual dimorphism of this invasive lizard is evident in the figure; the chameleon on the left is a female (lacking horns), the one on the right is a male (1 rostral, 2 ocular horns)

swallow snail shells whole (B. Holland et al. unpublished data); therefore, we force-fed chameleons intact shells. Water was used to initiate the swallowing reflex. Once the shell was ingested, time was recorded as time 0 .

In order to test different feeding scenarios, chameleons were then randomly divided into 2 groups, each corresponding to a different feeding treatment. Group I was fed live cockroaches Nauphoetacinerea sp., Pycnoscelusindicus sp., and Diploptera punctata (length: 1-2 cm), twice per day, until satiated, while Group II was not fed during the trial. Water was provided twice per day in both groups. To assess timing of the shell digestion and passage process, 3 to 4 replicate chameleons from each group were euthanized at the following intervals: $3,4,5,7$, and $8 \mathrm{~d}$. Chameleons that did not pass the shell were dissected and the position of the shell or shell fragments (PSH) within the digestive tract $(1=$ stomach, $2=$ proximal half of intestine, $3=$ distal half of intestine, 4 = passed) was recorded. Shells and or shell fragments were then washed with $99 \%$ ethanol and airdried, and the final weight was recorded (FWE). The percentage of digested shell mass (DSM) was determined per chameleon using the following formula:

$$
\text { DSM: }(\mathrm{IWE}-\mathrm{FWE}) \times 100 / \mathrm{IWE}
$$

Shells and shell fragments were digitally photographed, and images were used to separate shells into 5 discrete categories based on condition (CON): (1) intact shell with pitted and patchy, somewhat degraded periostracum ( 22\% digested mass), (2) 
digested apex, extensive pitting, some perforations through the shell ( $44 \%$ digested mass), (3) only the main body whorl remaining ( $60 \%$ digested mass), (4) only shell fragments remain $(\sim 82 \%$ digested mass), and (5) shell completely digested.

\section{Specimen collections for gut contents}

Jackson's chameleons were collected in the field by hand from a $2000 \mathrm{~m}^{2}$ area that lacks public access, located in the central Waianae Mountain Range (Puu Hapapa, Fig. 1) at about $800 \mathrm{~m}$ elevation. This site represents a native rain forest characterized by dense, high canopy (up to $90 \%$ canopy cover), dominated by endemic trees and shrubs such as Metrosideros polymorpha, Urera glabra, Pisonia spp., Ilex spp., Cyanea sp., and Perrotetia sandwicensis, and the tallest canopy exceeds $15 \mathrm{~m}$ in height. A longterm concerted botanical restoration effort has been underway here since 2009, including out-planting many rare plant species, weed removal, and invasive rat, slug and flatworm control (Oahu Army Natural Resource Program pers. comm.). This collection locality is the site of a recently completed invasive predator-proof fence, engineered and built to protect endangered tree snails from rats, predatory gastropods, flatworms, and chameleons. Chameleon surveys and collection occurred weekly from July 2012, when the barrier was closed, until February 2013, when the last chameleon was removed from inside the barrier. Surveys and conservation activities within the predator-proof structure have continued on a weekly basis, and no chameleons have been observed since then. Once the barrier was closed, chameleons were unable to pass in either direction, thus the number of chameleons within the perimeter during the collection period did not increase, with the only potential replacement of animals collected from within being due to births.

All chameleons collected were brought to the lab where they were euthanized, dissected, and their gut contents sorted and examined under dissecting scopes. All snail shells found were separated, identified, cleaned, dried, and digitally photographed. Photographs were used to assess shell condition (CON) and compared to condition of shells used in laboratory digestion trials to assign degradation category and estimate consumption time. All aspects of capture, handling, and euthanasia of Jackson's chameleons were conducted in accordance with protocols of the University of Hawaii Institutional Animal Care and Use Committee (IACUC).

\section{Statistical analyses}

In the laboratory shell digestion trials, differences in CON and DSM between fed and fasting chameleons within a given time interval were directly compared using Mann-Whitney and $t$-tests, respectively. Both CON and DSM were then compared over $24 \mathrm{~h}$ time intervals using a Friedman 1-way ANOVA (non-parametric ordinal data) and a regular 1-way ANOVA, respectively. Tukey tests were used for pairwise comparisons. Pearson correlations were used to assess the significance of the relationship between both CON and DSM over time. In addition, a second ANOVA was applied to compare DSM among categories of shell condition, and post hoc pairwise comparisons were made using Tukey tests.

\section{RESULTS}

\section{Laboratory component: shell digestion trials}

We used 37 adult Jackson's chameleons in laboratory feeding experiments: 15 females and 22 males. There was no significant difference in SVL between fed (Group I) and fasting (Group II) chameleons $\left(t_{1,35}=-1.3, \mathrm{p}=0.12\right)$ used in this trial. Twelve chameleons were used in Group I, while 25 individuals were included in Group II. For Group I, treatment was carried out for $5 \mathrm{~d}$ (see details below), and for Group II, $8 \mathrm{~d}$.

Our feeding trials indicated that food intake significantly shortened the passage time of the shell through the digestive tract of Jackson's chameleons. By Day 3, the shell had moved to the proximal portion of the intestine in $50 \%$ of fed (Group I) individuals (i.e. Position 2) and in the other $50 \%$, the shell was found in the distal half of the intestine (i.e. Position 3 ; Fig. 3). On Day 4, shells in 33\% of individuals of Group I were located in the distal portion of the intestine and $67 \%$ of the shells had passed (i.e. Position 4), while $100 \%$ of the shells had passed by Day 5 (Fig. 3). By contrast, in the fasting treatment (Group II), $100 \%$ of the shells remained in the stomach of chameleons (i.e. Position 1) for the duration of the trial (Fig. 3).

The process of shell digestion was not affected by feeding treatment (i.e. fed daily versus fasting). On Day 3, CON and DSM did not vary significantly between Groups I and II (CON: Mann-Whitney, $U=$ $6, Z=0.98$; DSM: $t$-test: $t=1.1 ; \mathrm{p}>0.05$ for all tests). Due to the fact that shells had passed the stomach by Day 3 in fed individuals, CON and the percentage of 


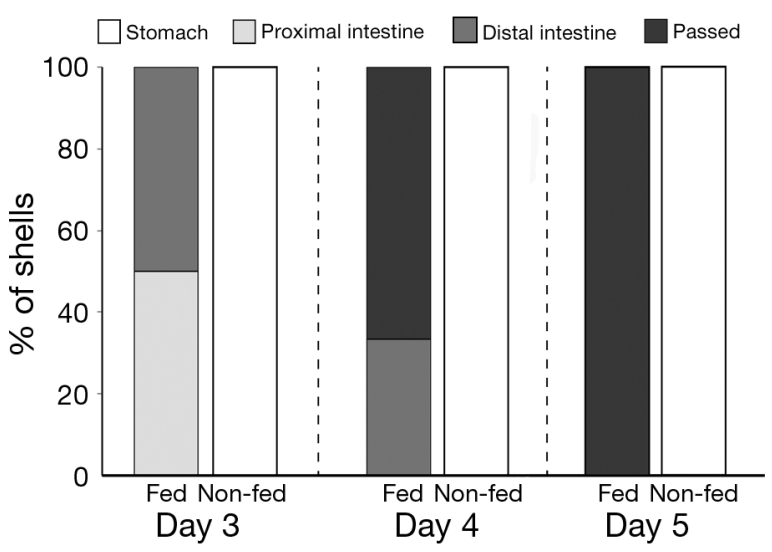

Fig. 3. Position of endangered tree snail shells in guts of daily fed (fed; $\mathrm{n}=15$ ) and fasting (non-fed; $\mathrm{n}=12$ ) Jackson's chameleons Trioceros jacksonii xantholophus during laboratory digestion trials, 3,4 , and $5 \mathrm{~d}$ after ingestion. Shells remained in the stomach of all 12 non-fed individuals for the duration of the experiment ( $8 d$, not shown), whereas after Day 5, all shells in fed chameleons were passed

DSM remained constant until the end of the trial (CON: $\mathrm{r}=0.01 ; \chi^{2}=2.1$. DSM: $\mathrm{r}=0.02$; ANOVA: $F_{1,15}=1.43 ; \mathrm{p}>0.05$ for all tests; Fig. 4). Contrarily, since shells remained in the stomach of starved chameleons until complete digestion (see above), both CON and DSM increased significantly over time (CON: $\mathrm{r}=0.82$; DSM: $\mathrm{r}=0.84, \mathrm{p}<0.05$ ) in these individuals, with significant differences detected among days (CON: $\chi^{2}=34.4, \mathrm{p}<0.01$; DSM: $F_{1,22}=22.43, \mathrm{p}<$ 0.01 ; Fig. 4). CON varied significantly among all days, with the exception of the period between Days 5 and 7 (Fig. 4A). A similar pattern was observed for DSM, with no significant differences detected between Days 7 and 8 (Fig. 4B). The percentage of DSM varied significantly among CON Categories 1 to 4 $\left(F_{3,25}=50.7, \mathrm{p}<0.001\right.$; Fig. 4$)$, increasing by $\sim 20 \% \mathrm{~d}^{-1}$ after Day 3. In $8 d, 66 \%$ of shells fed to individuals of Group II, independent of size, were completely digested (Category 5) and could not be detected, whereas $34 \%$ were found in the form of small fragments (Category $4 ;$ Fig. 5 ). Thus, the average rate at which Achatinella mustelina shell mass was digested by Jackson's chameleons in the laboratory was $12.5 \% \mathrm{~d}^{-1}$.

\section{Gut content analysis of field-collected specimens}

Of 45 Jackson's chameleons collected from Puu Hapapa (Fig. 1), 4 individuals (8.9\%) had at least 1 Achatinella mustelina shell present in the gut. Three
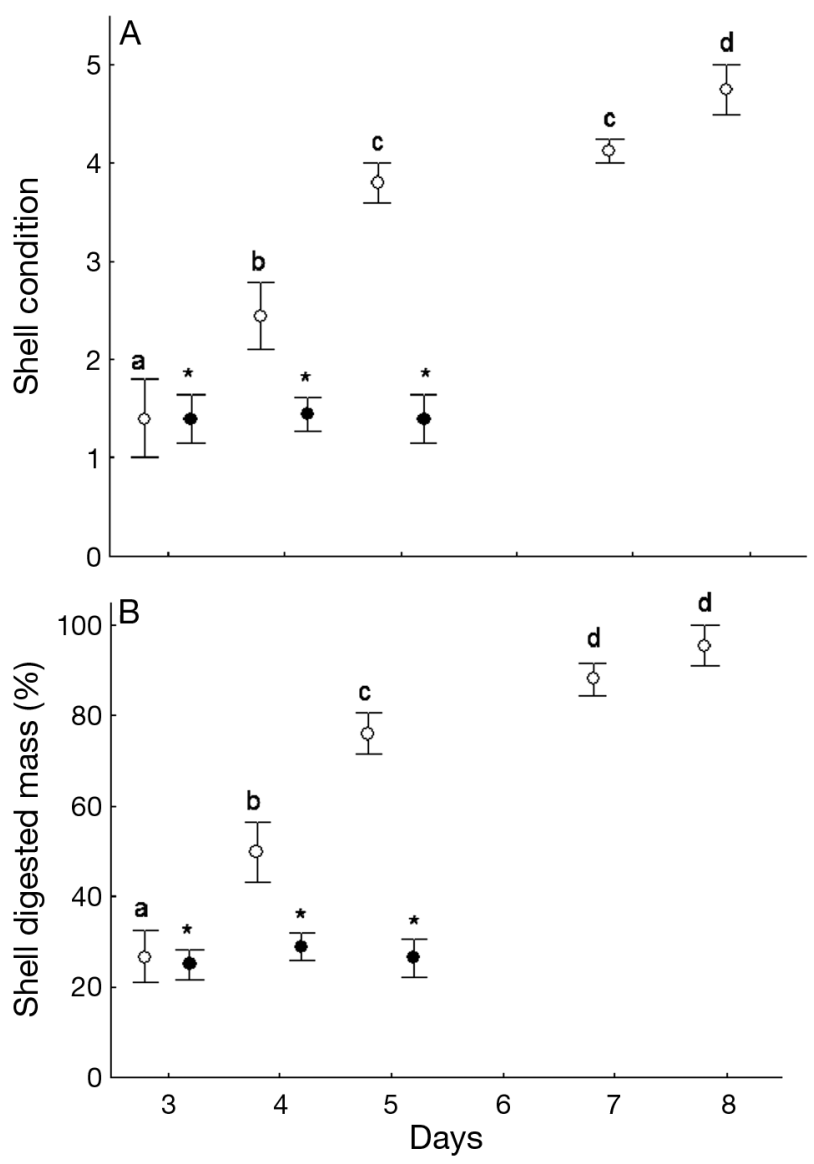

Fig. 4. (A) Shell condition and (B) percentage of digested mass of Achatinella mustelina shells over time in daily fed $(\bullet)$ and fasting (०) Jackson's chameleons Trioceros jacksonii xantholophus. Points show the mean values, whiskers indicate SE. Different lower case letters indicate significant differences in shell condition and percentage of digested shell mass among days in starved individuals (ANOVA, Tukey test, $\mathrm{p}<0.01$ ). Asterisks indicate no significant differences in both parameters over time for fed specimens

(ANOVA, $\mathrm{p}>0.05$ )

individuals (nos. 59, 73, and 74) had a single shell, while individual no. 71 had 5 shells, giving a total of 8 shells. The position of the shell within the gut, shell size, and shell condition per individual is summarized in Table 1. Only 1 shell was found in the proximal portion of the intestine (Position 2), which displayed a partially digested apex, extensive pitting, and holes passing through the shell, typical of shell Category 2. The rest of the shells had only the main body whorl remaining (Category 3 ), and were found in the stomach (Position 1) of the chameleons (Fig. 6, Table 1). Interestingly, of the 5 A. mustelina shells found in the stomach of chameleon no. 71, 1 was Category 1, 1 was Category 3, and 3 were Category 2 (Fig. 6, Table 1). 

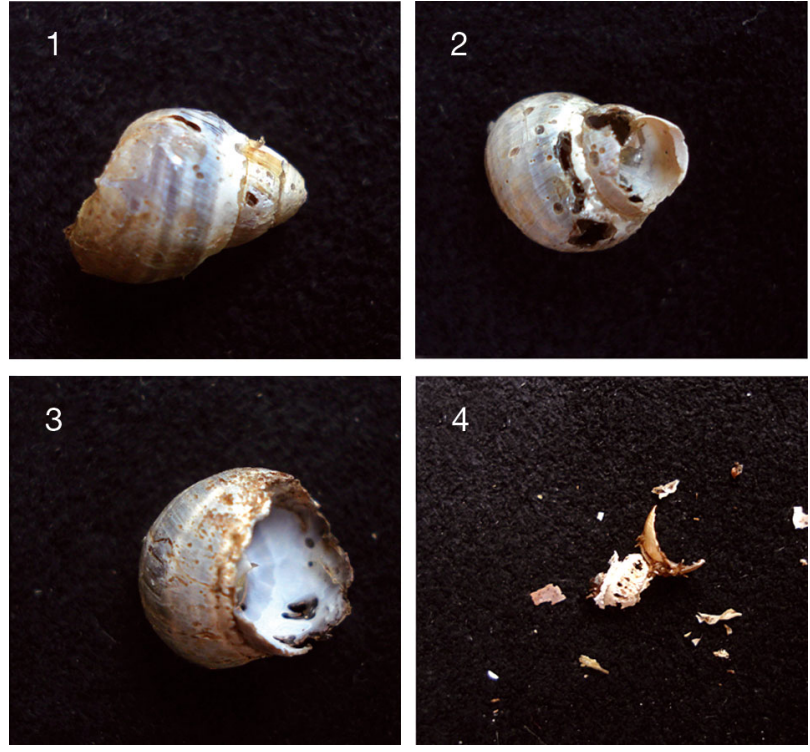

Fig. 5. Endangered Oahu tree snail Achatinella mustelina shells at different stages of digestion, expressed as categories of shell condition (CON: 1-4, see 'Experimental approach: feeding trials' in the 'Materials and methods' for a detailed description of each category; see Fig. 3 for shell condition versus time). Category 1: $\sim 22 \%$ digested mass. Category 2: $\sim 44 \%$ digested mass. Category 3: $\sim 60 \%$ digested mass. Category 4: $\sim 82 \%$ digested mass. Category 5 (not shown): shell completely digested

\section{DISCUSSION}

In light of the recent discovery that Jackson's chameleons prey on native island species (Holland et al. 2010), this investigation was designed as a followup study aimed at gaining insights to further assess their potential predatory threat, specifically on the endangered Hawaiian tree snail Achatinella mustelina. Thus, this study represents the first attempt to quantitatively evaluate impact and assess the threat by predation on an endangered tree snail by an invasive lizard. Our feeding trials allowed us to determine the passage time and digestion rates of A. mustelina shells under different feeding scenarios, and to develop a sequence of objective, discrete categories of shell condition that can be assigned to estimate residence time in the gut of this species. These results were useful not only in estimating the time of consumption of snails consumed by chameleons collected from the wild, but also for scaling up and quantifying the potential impact of Jackson's chameleons on endangered Hawaiian tree snails in a given area.

Passage time of A. mustelina shells through the gut of Jackson's chameleons was dramatically shortened by the amount of food supply (i.e. fed versus fasting).
Table 1. Achatinella mustelina. Summary of shells found in the stomachs of 45 Jackson's chameleons Trioceros jacksonii xantholophus collected from the Waianae Mountain Range (Puu Hapapa, see Fig. 1), on the Hawaiian Island of Oahu. Chameleon no. 71 had 5 shells in its stomach (labeled A to E here). For a description of the shell condition categories, see 'Materials and methods'

\begin{tabular}{|c|c|c|c|c|}
\hline ID & $\begin{array}{l}\text { No. of } \\
\text { shells } \\
\text { in gut }\end{array}$ & $\begin{array}{c}\text { Shell } \\
\text { dimensions } \\
(\mathrm{l} \times \mathrm{w}, \mathrm{mm})\end{array}$ & $\begin{array}{c}\text { Position } \\
\text { within } \\
\text { gut }\end{array}$ & $\begin{array}{c}\text { Shell } \\
\text { condition } \\
\text { category }\end{array}$ \\
\hline 59 & 1 & $6.58 \times 6.01$ & Stomach & 3 \\
\hline 71 & 5 & $\begin{array}{l}\text { A: } 10.09 \times 8.98 \\
\text { B: } 6.72 \times 6.33 \\
\text { C: } 6.39 \times 4.01 \\
\text { D: } 5.47 \times 4.29 \\
\text { E: } 7.82 \times 5.94\end{array}$ & Stomach & $1,2,3$ \\
\hline 73 & 1 & $7.28 \times 4.65$ & $\begin{array}{l}\text { Proximal } \\
\text { intestine }\end{array}$ & 2 \\
\hline 74 & 1 & $4.17 \times 3.86$ & Stomach & 3 \\
\hline
\end{tabular}

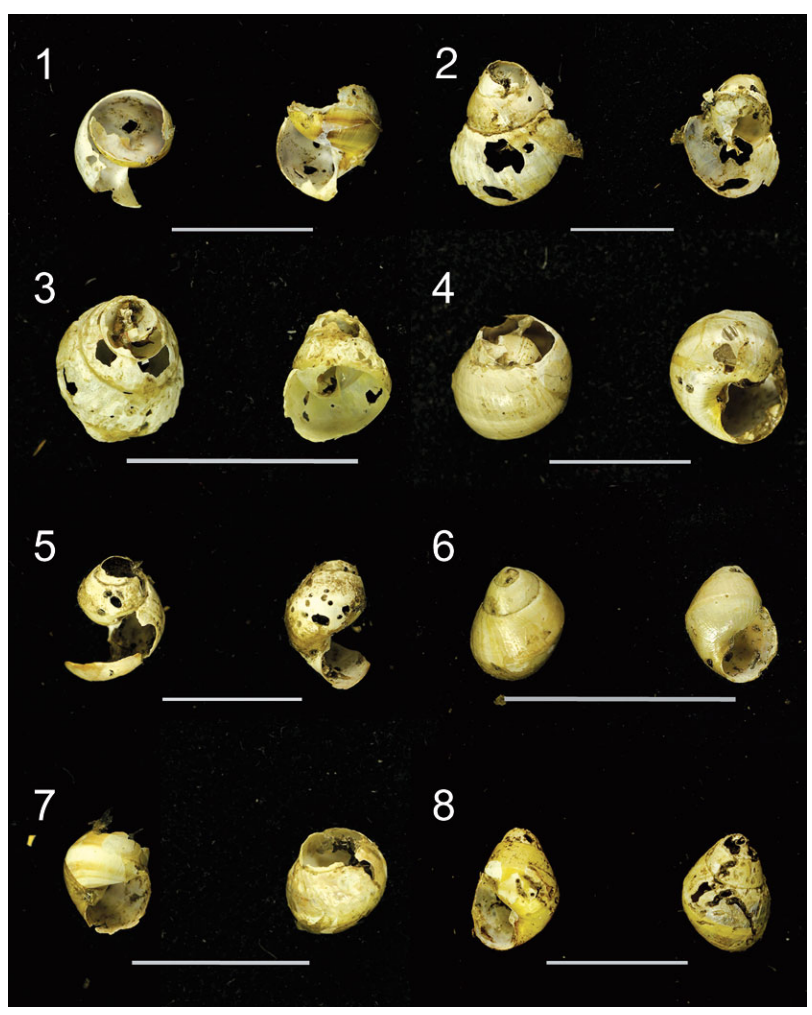

Fig. 6. Achatinella mustelina. Shells from gut contents of field-collected Jackson's chameleons Trioceros jacksonii xantholophus, collected at Puu Hapapa in the Waianae Mountains, Oahu (see Fig. 1). Each image shows 2 views for each of 8 shells found in the stomachs of 45 chameleons examined during this study (see Table 1 for dimensions and assigned shell condition category). Shell 1: Category 3 found in stomach of individual no. 59. Shell 3: Category 3 found in stomach of individual no. 74 . The remaining shells were found in the stomach of individual no. 71. Shell 2: Category

3, shell 6: Category 1, shells 4, 7, and 8: Category 2 
Thus, the daily ingestion of prey items (i.e. twice per day) besides the shell apparently facilitated the passage of stomach contents into the intestine, thus reducing the time shells remained in the stomach, where digestion takes place. In all fed Jackson's chameleons, shells had already moved out of the stomach by Day 3 and were passed in $5 \mathrm{~d}$, displaying a Category 2 digestion condition. In contrast, in fasting individuals, shells remained in the stomach for the duration of the experiment, achieving relatively advanced states of digestion (Categories 3 and 4), including complete digestion (Category 5), in $\sim 8 \mathrm{~d}$ (Fig. 2). These results are in concordance with those obtained by Waldschmidt et al. (1986) on the lizard Uta stansburiana, with daily fed individuals able to pass food within $\sim 5 \mathrm{~d}$, but taking twice as long when food ration was interrupted. It is well documented that food assimilation and passage time in lizards is affected by body temperature and body size (SVL; Van Damme et al. 1991, Xiang et al. 1996); however, in the present study, all specimens were housed at the same controlled temperature, and SVL did not vary significantly between fed and fasting individuals. In other words, the inference here is that the ingestion of prey items can have an indirect effect on shell digestion, reducing the time of exposure to the low $\mathrm{pH}$ environment of the stomach, and suggests that in areas where food is readily available, such as the Puu Hapapa collection site in this study (Fig. 1), shells will likely stay in the gut of Jackson's chameleons for significantly shorter periods than in areas/patches where prey is scarce.

\section{Threat assessment}

Despite a recent effort to model future range expansion for Jackson's chameleons (Rödder et al. 2011), detailed geographic distribution and population densities of this species have yet to be documented. The population at Puu Hapapa is evidently established, healthy, well fed, and clearly reproductive (authors' pers. obs.); it may therefore represent a useful model for other island locations that share basic habitat characteristics. The observed incidence of endangered A. mustelina tree snail predation in fieldcollected lizards might at first appear relatively low, since only 4 of the 45 (8.9\%) field-collected chameleons had A. mustelina shells in their guts. However, these chameleons were uniformly well fed and their stomach contents revealed diverse and abundant prey items (authors' unpubl. data), suggesting conditions leading to a relatively short passage time of shells through the gut of individuals from this area. Further support is given by the fact that 1 chameleon (no. 73) had an A. mustelina shell located within the proximal portion of the intestine exhibiting a state of digestion characteristic of Category 2 (Fig. 5, Table 1), which was achieved in $\sim 3$ d during our laboratory trials (Fig. $4 \mathrm{~A}$ ). Therefore, the actual impact of Jackson's chameleons on endangered tree snails may be far more substantial than this low number would suggest, due not only to the relatively short passage time these lizards exhibit when well fed, but also to the relatively short time required to completely dissolve an A. mustelina shell ( $~ 8 \mathrm{~d})$.

We estimated the density of Jackson's chameleons in this area (Puu Hapapa) by extrapolating from the 45 chameleons collected per $2000 \mathrm{~m}^{2}$ without replacement (see 'Materials and methods'), giving a value of 1 chameleon per $44 \mathrm{~m}^{2}$. We might assume that at any given time, about $9 \%$ of these chameleons prey on snails, or an instructive way to view the data is that every 3 to $4 \mathrm{~d}$, 45 chameleons can potentially consume 8 snails. Extrapolating these figures to a period of $1 \mathrm{yr}$, for every $2000 \mathrm{~m}^{2}$, chameleons at this density could consume 730 to 974 tree snails. However, it should be noted that this estimate may be conservative, because the density of chameleons could be substantially higher in the future, or in other localities. For example, Kraus et al. (2012) reported a density of 173 chameleons per $2000 \mathrm{~m}^{2}$ on the island of Maui. At this population density, we estimate a loss rate of 2806 to 3744 snails $\mathrm{yr}^{-1}$, per 0.2 ha. The estimated feeding frequency of $72 \mathrm{~h}$ may also be conservative, since our gut content analyses revealed that Jackson's chameleons have the potential to feed on A. mustelina at an even higher frequency, snail density permitting. For instance, chameleon no. 71 had 5 shells in its stomach in various states of degradation, corresponding to Categories 1, 2, and 3. According to our laboratory experiments, shells in the stomach went from Category 1 to 3 in $\sim 48 \mathrm{~h}$, suggesting that this individual likely ingested $A$. mustelina on 3 consecutive days.

Extrapolation of this estimated rate of loss of endangered snails across the landscape is alarming, and this projection is devastating when considered in light of snail species on the brink of extinction, with remarkably slow natural growth and reproductive rates, and extremely protracted replacement potential. A. mustelina suffers $98 \%$ natural mortality during the first $4 \mathrm{yr}$ of life, reaching maturity in 5 to $7 \mathrm{yr}$, and must reproduce for $12 \mathrm{yr}$ to achieve replacement (Hadfield \& Miller 1989). Another factor that renders A. mustelina particularly vulnerable to chameleons is 
that fact that both species are exclusively arboreal (USFWS 1993, Losos et al. 1993) and thus they occupy shared habitat. Jackson's chameleons are cruise foragers capable of actively searching for food (Hagey et al. 2010), which translates into a potential increased possibility of an encounter with the sedentary tree snails. Thus far, no specific or effective management strategy has been developed for Jackson's chameleons in Hawaii. The only control measure available is manual search and capture, and effective protection of native resources includes installation of predator exclosure structures specifically designed to prevent entry by these efficient climbers.

Although there are currently no restrictions on purchase, capture, or keeping Jackson's chameleons as pets in Hawaii, release is illegal. The public, however, is generally unaware of this (authors' pers. obs.), and there have been no prosecutions because of the lack of enforcement. Jackson's chameleons make challenging pets, due primarily to the diversity of prey species required as food, and therefore many pet chameleons are released (Kraus et al. 2012). This has likely led to ongoing range expansions in the Hawaiian Islands, where chameleons are available via the pet trade. Due to the combination of a large and possibly expanding range (Rödder et al. 2011), predation on diverse taxa (Holland et al. 2010, Kraus \& Preston, 2012, Kraus et al. 2012), and high population densities, this species poses a serious threat to Hawaiian fauna. As such, it is high time that the state legislature acknowledges this problem and alters regulations accordingly, such that chameleons are no longer available via the pet trade.

\section{Regional implications outside of Hawaii}

Jackson's chameleons represent one of the most popular species in the pet trade on an international scale. Between 1977 and 1982, more than 80000 Jackson's chameleons were exported from Kenya, with most of the specimens destined for the US market, as well as, for example, Japan, several European countries, and South Africa (Carpenter et al. 2004). In addition, release of chameleons into the wild has been reported at a number of other localities, including the Marshall Islands, Morro Bay (California), South Africa, and the Florida Keys. Thus, this predator could pose a serious threat to native fauna globally, and particularly to threatened or endangered taxa in tropical and subtropical ecosystems. Impact assessment data therefore have relevance for re- source management in all regions where chameleons either have become established or have the potential to be released in the future.

Acknowledgements. We thank the staff of the Oahu Army Natural Resources Program, especially V. Costello, S. Joe, J. Tanino, J. Rohrer, and K. Kawelo, for their commitment to Hawaiian tree snail conservation and their diligence and dedication to invasive predator control and habitat stabilization. We thank members of the Hawaiian Tree Snail Conservation Lab, including M. J. Wright and T. A. Hooper Smith, B. Dietrich, C. Artiles, and C. Howard for lab assistance. This project was supported by US Army Cooperative Agreement-W9126G-11-2-0066. All handling and care of chameleons was conducted in compliance with IACUC protocol no. 1105-2.

\section{LITERATURE CITED}

Carlquist SJ (1970) Hawaii: a natural history: geology, climate, native flora and fauna above the shoreline. Natural History Press, Garden City, NY

Carpenter AI, Rowcliffe JM, Watkinson AR (2004) The dynamics of the global trade in chameleons. Biol Conserv 120: 291-301

Chiaverano LM, Wright MJ, Holland BS (2014) Home on the range: Movement behavior is habitat-dependent in invasive Jackson's chameleons in Hawaii. J Herpetol 48 (in press)

Cowie RH (2001) Invertebrate invasions on Pacific Islands and the replacement of unique native faunas: a synthesis of the land and freshwater snails ${ }^{*}$ Contribution no. 2001001 of Bishop Museum's Pacific Biological survey. Biol Invasions 3:119-136

- Dobson AP, Rodriguez JP, Roberts WM, Wilcove DS (1996) Geographic distribution of endangered species in the United States. Science 275:550-553

Hadfield MG, Miller SE (1989) Demographic studies on Hawaii's endangered tree snails: Partulina proxima. Pac Sci 43:1-16

> Hagey TJ, Losos JB, Harmon LJ (2010) Cruise foraging of invasive chameleon (Chamaeleo jacksonii xantholophus) in Hawaii. Breviora 519:1-7

Holland BS (2009) Island flora and fauna: snails. In: Gillespie $\mathrm{R}$, Clague DA (eds) The encyclopedia of islands. Science Publishing Group, University of California Press, Los Angeles, CA, p 537-542

Holland BS, Hadfield MG (2007) Molecular systematics of the endangered O'ahu tree snail Achatinella mustelina (Mighels 1845): synonymization of subspecies and estimation of gene flow between chiral morphs. Pac Sci 61: 53-66

Holland BS, Christensen CC, Hayes KA, Cowie RH (2008) Biocontrol in Hawaii: a response to Messing (2007). Proc Hawaiian Entomol Soc 40:81-83

Holland BS, Montgomery SL, Costello V (2010) A reptilian smoking gun: first record of invasive Jackson's chameleon (Chamaeleo jacksonii) predation on native Hawaiian species. Biodivers Conserv 19:1437-1441

IUCN (2013) IUCN Red List of Threatened Species. Version 2013.2. www.iucnredlist.org

Kraus F, Preston D (2012) Diet of the invasive lizard Chamaeleo jacksonii (Squamata: Chamaeleonidae) at a wetforest site in Hawaii. Pac Sci 66:397-404 
Kraus F, Medeiros A, Preston D, Jarnevich CS, Rodda GH (2012) Diet and conservation implications of an invasive chameleon, Chamaeleo jacksonii (Squamata: Chamaeleonidae) in Hawaii. Biol Invasions 14:579-593

Losos JB, Walton BM, Bennett AF (1993) Trade-offs between sprinting and clinging ability in Kenyan chameleons. Funct Ecol 1993:281-286

McKeown S (1991) Jackson's chameleons in Hawaii are the recently described Mt. Kenya subspecies, Chamaeleo jacksonii xantholophus. Bull Chicago Herpetol Soc 26:49

McKeown S (1996) A field guide to reptiles and amphibians in the Hawaiian Islands. Diamond Head Publishing, Los Angeles, CA

Mead AR (1979) Economic malacology: with particular reference to Achatina fulica. In: Fretter V, Peake J (eds) Pulmonates, Vol 2B. London Academic Press, London

Necas P (1999) Chameleons: Nature's hidden jewels. Chimaira, Frankfurt am Main

Rödder D, Bohme W, Lotters S (2011) 'Chamaliens' on the Hawaiian Islands: spatial risk assessment for the invasive Jackson's chameleon (Chamaeleonidae). Salamandra 47: 36-42

Spawls S, Rotich D (1997) An annotated checklist of the lizards of Kenya. J East Afr Nat Hist 86:61-83

Editorial responsibility: Luca Luiselli,

Rome, Italy
USFWS (United States Fish and Wildlife Service) (1981) Endangered and threatened wildlife and plants; listing the Hawaiian (Oahu) tree snails of the genus Achatinella as endangered species. Fed Reg 46:3178-3182

USFWS (United States Fish and Wildlife Service) (1993) Recovery Plan: Oahu tree snails of the genus Achatinella. US Department of the Interior, US Fish and Wildlife Service, Portland, OR

Van Damme R, Bauwens R, Verheyen RF (1991) The thermal dependence of feeding behavior, food consumption and gut-passage time in the lizard Lacerta vivipara Jacquin. Funct Ecol 5:507-517

Waldschmidt SR, Jones SM, Porter WA (1986) The effect of body temperature and feeding regime on activity, passage time, and digestive coefficient in the lizard Uta stansburiana. Physiol Zool 59:376-383

Waring GH (1997) Preliminary study of the behavior and ecology of Jackson's chameleons of Maui, Hawaii. Report for USGS/BRD/PIERC Haleakala Field Station. Hawaii Ecosystems at Risk (HEAR) project. www.hear.org

Xiang J, Weiguo D, Pingyue S (1996) Body temperature, thermal tolerance and influence of temperature on sprint speed and food assimilation in adult grass lizards, Takydromus septentrionalis. J Therm Biol 3:55-61

Submitted: December 13, 2013; Accepted: January 28, 2014 Proofs received from author(s): April 29, 2014 